\title{
Futuro del TPP ante el retiro de EE.UU.
}

\author{
Carlos Posada*
}

\section{RESUMEN}

El presente artículo tiene por finalidad analizar cuáles han sido los antecedentes que llevaron a la negociación y firma de un ambicioso Acuerdo Comercial Multilateral -TPP, que tenía por propósito establecer una zona comercial entre países del Sudeste Asiático y países de América, que en conjunto representan aproximadamente el $40 \%$ de la economía mundial y entre sus fronteras quedan comprendidas 800 millones de personas.

Este esfuerzo que se inició con la negociación del P4, fue luego ampliado con la participación de EE.UU. y los demás países que lo siguieron. Entre los temas que comprende este Acuerdo, hay algunos que causan rechazo por parte de algunos sectores, esto debido a las implicancias que genera para sus economías.

Pero, debido a la posición declarada por el actual presidente de EE.UU. de América (EE UU.) Donald Trump, este ambicioso acuerdo ha quedado prácticamente sin futuro, debido a que anunció el retiro formal de dicho país del proceso, lo que significó que varios de los países participantes expresaran igualmente su intención de retirarse del mismo.

En los siguientes meses veremos los efectos que surgen.

Palabras clave: Acuerdo de Asociación Transpacífico, acuerdos comerciales, Asía Pacífico, EE.UU., Tratado de Libre Comercio de América del Norte (TLCAN), negociaciones comerciales, Perú, P4.

\footnotetext{
* Abogado por la Universidad de Lima, con estudios de posgrado en Gestión de Comercio Exterior en la Universidad ESAN. Exviceministro de Comercio Exterior y Exsuperintendente de Aduanas. Actualmente vicepresidente del Consejo Nacional de Usuarios del Sistema de Distribución Física Internacional (CONUDFI) y director ejecutivo de Comercio Exterior de la Cámara de Comercio de Lima, Perú. Correo electrónico: cposada@camaralima.org.pe.
} 


\section{Future of the TPP agreement facing of the US withdrew}

\section{Abstract}

The purpose of this article is to analyze the background of the negotiation and signing of an ambitious Multilateral Trade Agreement - TPP, whose purpose was to establish a commercial zone between Southeast Asian countries and countries of the Americas, which together represent approximately $40 \%$ of the world economy with a population of around 800 million people.

This effort, which began with the negotiation of $\mathrm{P} 4$, was later expanded with the inclusion of the United States of America and other countries that joined the process. Among the issues covered by this Agreement, there are some that cause rejection by some sectors, due to the implications for their economy.

However, because of the position declared by the current President of the United States, Donald Trump, this process to reach a comprehensive and ambitious Agreement has stopped, and after that, several members have also expressed their intention to withdraw the process too. In the following months we will see the effects of those decisions.

Keywords: Trans Pacific Partnership Agreement, Free Trade Agreements, Asia Pacific, United States, North America Free Trade Agreement (NAFTA), Trade Negotiations, Peru, P4. 
Con la finalidad de abordar el tema en forma integral, presentaremos a continuación los antecedentes que llevaron a la negociación del Acuerdo de Asociación Transpacífico (TPP por sus siglas en inglés).

\section{Historia del P4}

El antecedente general de este proceso se dio a través de la negociación del Acuerdo Estratégico Transpacífico de Asociación Económica, conocido como el P4, el cual fue negociado entre Nueva Zelandia, Singapur (ambos países a su vez ya habían negociado y suscrito en 2000 un Acuerdo de Acercamiento Económico - NZ/SCEP), Chile y Brunei Darussalam (Ministerio de Comercio y Relaciones Exteriores de Nueva Zelandia, 2005).

El inicio de las negociaciones del Acuerdo, fue anunciado por el presidente de Chile, el primer ministro de Nueva Zelandia y el primer ministro de Singapur, durante la reunión de Jefes de Estado del APEC, celebradas en 2002, bajo el deseo común de crear un acuerdo comercial amplio, que estableciera altos estándares en las reglas comerciales y ayudara a promover la liberalización comercial y facilitara el comercio al interior de la región del APEC.

La primera ronda de negociaciones se llevó a cabo en septiembre 2003, en Singapur. Antes del final de dicho año Chile solicitó una pausa en las negociaciones para realizar consultas con su sector privado. Las negociaciones prosiguieron a mediados del año 2004, luego de la visita del presidente de Chile a Nueva Zelandia y Singapur. Entre agosto de 2004 y abril de 2005, se desarrollaron cuatro rondas de negociación adicionales. Brunei-Darussalam, país que se había constituido como observador de las negociaciones desde la segunda ronda, solicitó ser parte del acuerdo, en calidad de miembro fundador, antes del desarrollo de la última ronda en abril de 2005. Considerando su tardío acercamiento y el pequeño tamaño de su economía, se le otorgó una moratoria de dos años para culminar las negociaciones respecto de los temas relativos a compras públicas, servicios y algún margen de flexibilidad en cuanto a sus obligaciones sobre el capítulo de competencia.

Cómo se indicara líneas arriba, el acuerdo base de la negociación fue el NZ/SCEP vigente desde el 1 de enero de 2001 el mismo que se encuentra vigente en forma conjunta con el $\mathrm{P} 4$, lo que significa que los nacionales de ambos países pueden invocar uno u otro acuerdo, según su conveniencia.

El P4 fue suscrito el 18 de julio de 2005, en Wellington, Nueva Zelandia. El texto del mismo puede ser consultado en la biblioteca del SICE (SICE, 2017).

Los primeros países en cumplir con el depósito del instrumento de ratificación del acuerdo fueron Nueva Zelandia y Singapur, los cuales lo hicieron el 20 y el 28 de 
abril de 2006, respectivamente. Su entrada en vigencia para ambos países fue efectiva a partir del 1 de mayo de 2006.

En el caso de Chile, el Congreso aprobó el acuerdo el 5 de septiembre de 2006, siendo depositado el instrumento de ratificación el 9 de octubre de 2006, y entró en vigencia para este país el 8 de noviembre de 2006. En el caso de Brunei Darussalam, el documento de ratificación fue depositado el 29 de junio de 2009, y entró en vigencia el 29 de julio de 2009.

A continuación mostramos cuáql era el escenario comercial que tenían los países integrantes del P4 antes y durante la etapa de las negociaciones del acuerdo.

Así, en la figura siguiente podemos observar cuál era el saldo comercial de estos países entre los años 2001 a 2005.

Figura 1. Saldo comercial países del P4

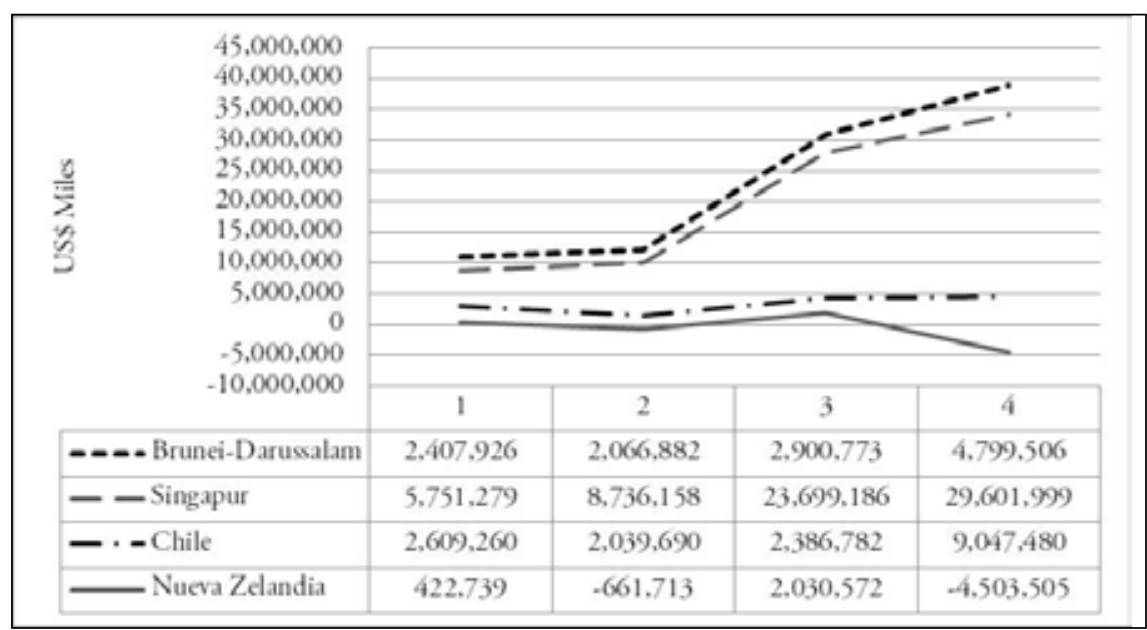

Fuente: TRADEMAP.

En las tablas 1 a 4 brindamos la información del valor del comercio entre los cuatro países en el periodo 2001 a 2005.

Tabla 1. Intercambio comercial de Brunei con los demás países del P4 (US\$ miles)

\begin{tabular}{|l|c|c|c|c|c|}
\hline & \multicolumn{1}{|c|}{2001} & 2002 & \multicolumn{1}{c|}{2003} & \multicolumn{1}{c|}{2004} & \multicolumn{1}{c|}{2005} \\
\hline EXPORTACIONES & 324899 & 205431 & 281933 & 284658 & 232181 \\
\hline IMPORTACIONES & 264727 & 274309 & 252204 & 265984 & 281455 \\
\hline SALDO & 60172 & -68878 & 29729 & 18674 & -49274 \\
\hline
\end{tabular}

Fuente: TRADEMAP. 
Tabla 2. Intercambio comercial Chile y los demás países del P4 (US\$ miles)

\begin{tabular}{|l|c|c|c|c|c|}
\hline & 2001 & 2002 & 2003 & 2004 & 2005 \\
\hline EXPORTACIONES & 41155 & 44992 & 60601 & 82193 & 101336 \\
\hline IMPORTACIONES & 52880 & 41400 & 38225 & 53181 & 74406 \\
\hline SALDO & -11725 & 3592 & 22376 & 29012 & 26930 \\
\hline
\end{tabular}

Fuente: TRADEMAP.

Tabla 3. Intercambio comercial Nueva Zelandia y los demás países del P4 (US\$ miles)

\begin{tabular}{|l|l|l|l|l|l|}
\hline & 2001 & 2002 & 2003 & 2004 & \multicolumn{1}{c|}{2005} \\
\hline EXPORTACIONES & 189840 & 196597 & 198262 & 277189 & 341298 \\
\hline IMPORTACIONES & 292975 & 355588 & 499909 & 842982 & 1002673 \\
\hline SALDO & 103135 & 158991 & 301647 & 565813 & 661375 \\
\hline
\end{tabular}

Fuente: TRADEMAP.

Tabla 4. Intercambio comercial Singapur y los demás países del P4 (US\$ miles)

\begin{tabular}{|l|c|c|c|c|c|}
\hline & 2001 & 2002 & 2003 & 2004 & \multicolumn{1}{c|}{2005} \\
\hline EXPORTACIONES & 848230 & 899787 & 1054270 & 1461103 & 1696169 \\
\hline IMPORTACIONES & 391442 & 447290 & 464648 & 505125 & 573638 \\
\hline SALDO & 456788 & 452497 & 589622 & 955978 & 1122531 \\
\hline
\end{tabular}

Fuente: TRADEMAP.

\section{Cómo se amplió al TPP}

En palabras del presidente de Chile Ricardo Lagos, con ocasión de presentar el proyecto para la aprobación del Acuerdo Estratégico Transpacífico de Asociación Económica (Biblioteca del Congreso Nacional de Chile, 2006):

Una de las características más importantes de este Acuerdo es que la cantidad y diversidad de materias que abarca es considerablemente más vasta que la de los Tratados de Libre Comercio convencionales. En efecto, junto con los líderes de Nueva Zelandia y Singapur, acordamos establecer una alianza estratégica que no solo abordara los temas económicos y comerciales tradicionales, sino también, privilegiara la asociatividad y la cooperación en tecnologias, inversiones, investigación, y el desarrollo de áreas como comercialización y distribución, entre otros temas.

$[\ldots]$

El objetivo central de esta definición fue establecer que el Acuerdo de Asociación, junto con liberalizar las relaciones económicas y comerciales, también debería contri- 
buir a que los cuatro países mejoren sus capacidades para competir en los mercados internacionales y particularmente en la región del Asia-Pacífico.

$[\ldots]$

De esta forma, el presente Acuerdo, junto con crear una zona de libre comercio conforme a las normas de la OMC, establece compromisos en materias económicas, financieras, tecnológicas y de cooperación. Asimismo, deja abierta la posibilidad para la incorporación de nuevos miembros a esta alianza estratégica. (Resaltado nuestro)

Son justamente esas características particulares del Acuerdo P4, lo que permiten deducir que su propósito es diseñar un acuerdo que sentará las bases para un futuro Acuerdo de Libre Comercio del Asia-Pacífico (Free Trade Area of the Asia-Pacific). Este tema se halla presente en las discusiones al interior del APEC desde 2004.

El acuerdo es, entonces, un acuerdo abierto que contempla la posibilidad de la adhesión de terceros países, con el objetivo de promover la creación de una alianza estratégica mayor para la liberalización del comercio en la región. El artículo 20.6 del propio acuerdo, además de indicar la apertura del mismo a futuras adhesiones, establece que los términos de tales adhesiones tomarán en cuenta las circunstancias de la economía APEC o del Estado que pretenda adherirse, con especial énfasis a los cronogramas de tiempo para las liberalizaciones comprometidas.

En virtud a esta disposición y antes que transcurrieran los dos años de la entrada en vigencia del acuerdo, EE.UU., a través de la Oficina del Representante Comercial (USTR por sus siglas en inglés), anunció su intención de participar en las negociaciones sobre inversión y servicios financieros que los miembros del P4 llevaron a cabo en marzo de 2008.

Para septiembre de 2008, el gobierno de EE.UU. y los miembros del P4 anunciaron el inicio del proceso de negociación con miras a que el primero de los nombrados, formalizara su ingreso al Acuerdo Estratégico Transpacífico de Asociación Económica.

La participación de EE.UU. se vio motivada, a nuestro entender, por el rápido crecimiento de acuerdos comerciales que se venían dando en la región del Asia Pacífico. Consideremos que los países del Este Asiático se vieron en la necesidad de forjar acuerdos comerciales entre sí a fin de lograr la mejora de su competitividad. En el año 1980, apenas se habían suscrito 22 acuerdos en dicha región, mientras que para el año 2008, ya se habían suscrito 152 acuerdos entre dichos países y ya estaban en proceso de negociación otros 100. El hecho que estos países busquen asegurar su crecimiento económico y fortalecimiento de sus capacidades, y a su vez agruparse para formar bloques económicos relativamente fuertes, hace atractiva la región.

Tal como lo señaló Stratford (2008), hace casi nueve años atrás: 
[...] hay razones políticas detrás de la decisión de EE.UU. de unirse al P4. Su interés está centrado en mantener una mano en la formación de nuevos acuerdos en el Asia, para evitar que se llegue a formar una Zona de Libre Comercio Pan Asiática sin su participación.

Es evidente que potencias como China o la propia Unión Europea pudieran interesarse en tener participación en esquemas comerciales en dicha región, algo que no resultaría muy cómodo para los intereses comerciales de EE.UU.

\section{Ingreso del Perú}

Ante el anuncio de EE.UU., el Perú anunció la decisión de participar en el proceso de negociación del Acuerdo comprehensivo, Trans Pacific Partnership - TPP, en el marco de la Cumbre de Líderes de APEC efectuada en noviembre de 2008 en Lima, Perú. Este anuncio fue formalizado el 1 de diciembre de 2008 mediante carta enviada por el Ministerio de Comercio Exterior y Turismo del Perú al Ministerio de Comercio y Asuntos Exteriores de Nueva Zelandia y aceptado el 10 de febrero de 2009.

Debemos hacer notar que en la misma Cumbre, tanto Australia como Vietnam expresaron su decisión de participar en el mismo proceso.

En este punto debemos preguntarnos cuál era el interés del Perú en formar parte de este acuerdo multilateral, dado que a dicha fecha, el Perú ya había negociado un Acuerdo de Promoción Comercial con EE.UU., Tratados de Libre Comercio con Chile, con Singapur. Veamos cuál era el intercambio comercial del Perú con los otros países con los cuales se inició el proceso de negociaciones:

Tabla 5. Comercio bilateral entre Perú y Australia - Periodo 2001 a 2007 (US\$ miles)

\begin{tabular}{|l|c|c|c|c|c|c|c|}
\hline & $\begin{array}{c}\text { Valor en } \\
2001\end{array}$ & $\begin{array}{c}\text { Valor en } \\
2002\end{array}$ & $\begin{array}{c}\text { Valor en } \\
2003\end{array}$ & $\begin{array}{c}\text { Valor en } \\
2004\end{array}$ & $\begin{array}{c}\text { Valor en } \\
2005\end{array}$ & $\begin{array}{c}\text { Valor en } \\
2006\end{array}$ & $\begin{array}{c}\text { Valor en } \\
2007\end{array}$ \\
\hline $\begin{array}{l}\text { Total exportaciones } \\
\text { desde Perú }\end{array}$ & 35730 & 34586 & 53129 & 49503 & 54562 & 38286 & 97850 \\
\hline $\begin{array}{l}\text { Total importaciones } \\
\text { a Perú }\end{array}$ & 42703 & 25174 & 28186 & 46876 & 46876 & 59022 & 67088 \\
\hline SALDO & -6973 & 9412 & 24943 & 2627 & -8821 & -20736 & 30762 \\
\hline
\end{tabular}

Fuente: TRADEMAP. 
Tabla 6. Comercio bilateral entre Perú y Brunei Darussalam - Periodo 2001 a 2007 (US\$ miles)

\begin{tabular}{|l|c|c|c|c|c|c|c|}
\hline & $\begin{array}{c}\text { Valor en } \\
2001\end{array}$ & $\begin{array}{c}\text { Valor en } \\
2002\end{array}$ & $\begin{array}{c}\text { Valor en } \\
2003\end{array}$ & $\begin{array}{c}\text { Valor en } \\
2004\end{array}$ & $\begin{array}{c}\text { Valor en } \\
2005\end{array}$ & $\begin{array}{c}\text { Valor en } \\
2006\end{array}$ & $\begin{array}{c}\text { Valor en } \\
2007\end{array}$ \\
\hline $\begin{array}{l}\text { Total exportaciones } \\
\text { desde Perú }\end{array}$ & 0 & 0 & 0 & 12 & 3 & 0 & 0 \\
\hline $\begin{array}{l}\text { Total importaciones } \\
\text { a Perú }\end{array}$ & 17 & 1 & 0 & 1 & 0 & 2 & 0 \\
\hline SALDO & -17 & -1 & 0 & 11 & 3 & -2 & 0 \\
\hline
\end{tabular}

Fuente: TRADEMAP.

Tabla 7. Comercio bilateral entre Perú y Nueva Zelandia - Periodo 2001 a 2007 (US\$ miles)

\begin{tabular}{|l|r|r|r|r|r|r|r|}
\hline & $\begin{array}{c}\text { Valor en } \\
2001\end{array}$ & $\begin{array}{c}\text { Valor en } \\
2002\end{array}$ & $\begin{array}{c}\text { Valor en } \\
2003\end{array}$ & $\begin{array}{c}\text { Valor en } \\
2004\end{array}$ & $\begin{array}{c}\text { Valor en } \\
2005\end{array}$ & $\begin{array}{c}\text { Valor en } \\
2006\end{array}$ & $\begin{array}{c}\text { Valor en } \\
2007\end{array}$ \\
\hline $\begin{array}{l}\text { Total exportaciones } \\
\text { desde Perú }\end{array}$ & 1977 & 3193 & 3720 & 6242 & 5634 & 7616 & 11114 \\
\hline $\begin{array}{l}\text { Total importaciones } \\
\text { a Perú }\end{array}$ & 34728 & 22562 & 16204 & 23358 & 17718 & 19432 & 22376 \\
\hline SALDO & -32751 & -19369 & -12484 & -17116 & -12084 & -11816 & -11262 \\
\hline
\end{tabular}

Fuente: TRADEMAP.

Tabla 8. Comercio bilateral entre Perú y Vietnam - Periodo 2001 a 2007 (US\$ miles)

\begin{tabular}{|l|c|c|c|c|c|c|c|}
\hline & $\begin{array}{l}\text { Valor en } \\
2001\end{array}$ & $\begin{array}{c}\text { Valor en } \\
2002\end{array}$ & $\begin{array}{c}\text { Valor en } \\
2003\end{array}$ & $\begin{array}{c}\text { Valor en } \\
2004\end{array}$ & $\begin{array}{c}\text { Valor en } \\
2005\end{array}$ & $\begin{array}{c}\text { Valor en } \\
2006\end{array}$ & $\begin{array}{c}\text { Valor en } \\
2007\end{array}$ \\
\hline $\begin{array}{l}\text { Total exportaciones } \\
\text { desde Perú }\end{array}$ & 8666 & 4674 & 10646 & 19208 & 29156 & 35511 & 48395 \\
\hline $\begin{array}{l}\text { Total importaciones } \\
\text { a Perú }\end{array}$ & 3350 & 3182 & 4689 & 10349 & 15795 & 19754 & 26565 \\
\hline SALDO & 5316 & 1492 & 5957 & 8859 & 13361 & 15757 & 21830 \\
\hline
\end{tabular}

Fuente: TRADEMAP.

Desde el punto de vista comercial, incrementar su comercio con Australia, Nueva Zelandia y Vietnam, era uno de los atractivos. Brunei resultaba ser uno de los países con los cuales no se esperaba un salto espectacular en nuestro intercambio comercial, pero era uno de los países fundadores del esquema. Dadas las cosas, considerando la presencia de EE.UU. en la negociación y la oportunidad de ser uno de los países integrantes del nuevo esquema comercial que planteaba esta negociación, hacía atractivo para los intereses nacionales el participar en este proceso. 


\section{Proceso de las negociaciones}

Las negociaciones del TPP se llevaron a cabo a través de diecinueve rondas ${ }^{1}$. La primera de ellas se desarrolló del 15 al 19 de marzo de 2010, en la ciudad de Melbourne, Australia. En esta es de destacar la posición peruana relativa a preservar la vigencia de los acuerdos bilaterales existentes entre las partes presentes en la negociación, así como asegurar la coherencia entre el futuro TPP y dichos acuerdos bilaterales en algunas disciplinas específicas ligadas a acceso a mercados, servicios, defensa comercial, compras públicas y solución de controversias, entre otros.

La segunda ronda tuvo lugar en San Francisco en junio de ese mismo ańo, la que fue seguida de una reunión realizada en Lima en agosto. La tercera ronda se celebró en Brunei, Darussalam en octubre y en ella intervinieron veinticuatro grupos negociadores, y Malasia fue aceptada para incorporarse a la negociación sumándose a los otros ocho países participantes (Australia, Brunei, Chile, Estados Unidos, Nueva Zelandia, Perú, Singapur y Vietnam). La cuarta ronda se desarrolló en Auckland, Nueva Zelandia, en diciembre; mientras que la quinta fue en Santiago de Chile en febrero de 2011.

En esta última ronda es de destacar el hecho que, la preocupación por el avance de las negociaciones, llevó a los países a establecer un grupo de medidas correctivas, las cuales se señalan a continuación:

- Instruir a los negociadores a abordar los temas de fondo y no distraer el tiempo en temas de formatos.

- Evaluar y asignar el tiempo adecuado a cada grupo de negociación en las siguientes rondas.

- Recoger todas las propuestas existentes y consolidarlas como textos de negociación en cada grupo en el que aún no exista y permitir que los países continúen enviando nuevas propuestas.

- Evitar la realización de seminarios y talleres que tomen el tiempo de las negociaciones, los mismos que además se realizarán solamente en función de las necesidades de fortalecimiento de capacidades o por su aporte al proceso negociador.

- Cada grupo debe acordar por consenso la agenda de trabajo en cada ronda.

- Concentrar los eventos para conjuntos con los stakeholders a un día completo antes del inicio de cada ronda.

1 Para mayor detalle de estas rondas véase: http://www.sice.oas.org/TPD/TPP/TPP_s.ASP 
Posteriormente, tendría lugar la sexta ronda en Singapur, entre marzo y abril de 2011; la séptima fue en junio en Vietnam; la octava en setiembre en Estados Unidos; la novena en octubre en el Perú mientras que la décima se celebraría en diciembre en Malasia.

Durante 2012 se efectuaron las siguientes rondas de negociaciones: la undécima en marzo en Australia; la duodécima, decimotercera y decimocuarta en mayo, julio y setiembre respectivamente, todas en Estados Unidos; y la decimoquinta en diciembre en Nueva Zelandia.

En marzo de 2013 se desarrolló la decimosexta ronda en Singapur y en abril comienzan los trámites para la inclusión del Japón en estas negociaciones. Se especuló sobre el ingreso de este país, debido a que muchos analistas señalaban a EE.UU. como el principal interesado para cerrarle el paso a China, país que mantenía el status de observador. Pero lo evidente es que Japón necesitaba ser parte del TPP, debido a que su economía requería integrarse al Asia, en tanto ya no es posible el crecimiento de su mercado interno.

Luego, tuvo lugar la decimoséptima ronda en Lima durante el mes de mayo del mismo año, mientras que la decimoctava se realizó en julio en Malasia y la decimonovena y última en agosto en Brunei Darussalam.

Concluidas estas rondas, los Ministros de Comercio de los Estados negociadores del TPP sostuvieron diversas y sucesivas reuniones en Indonesia, Singapur, Vietnam, Australia y China de octubre de 2013 a noviembre de 2014, para que en diciembre se produjera una reunión final entre los jefes de los equipos negociadores del TPP en la ciudad de Washington.

\section{Cierre de la negociación y firma}

El día 4 de octubre de 2015, en reunión de los ministros de Comercio Exterior de los países integrantes del TPP, se anunció en Atlanta, Georgia, la conclusión del proceso de negociaciones del Acuerdo Comercial más ambicioso del siglo XXI.

Para EE.UU., cuyo presidente lo hizo suyo e impulsó las negociaciones, el Acuerdo nivelaba el campo de juego para los productores estadounidenses, introdujo fuertes compromisos laborales y en materia de medio ambiente, siendo estos compromisos exigibles, a diferencia de acuerdos anteriores.

Para México, el Acuerdo abre oportunidades de negocio en seis mercados de AsiaPacífico (Australia, Brunei, Malasia, Nueva Zelandia, Singapur y Vietnam), además de fortalecer la integración de las cadenas productivas de México, EE.UU. y Canadá. 
Para el Perú, de acuerdo a lo señalado por el Ministerio de Comercio Exterior y Turismo, el TPP era una oportunidad para consolidar la presencia en el Asia-Pacífico, zona de gran importancia para el país, y que brinda un mercado diversificado para el desarrollo de nuevos productos de exportación, el comercio de servicios, la atracción de inversiones, la movilidad de personas de negocios, entre otros.

La participación del Perú permitía identificar e introducir nuevos temas de interés no abordados en los actuales acuerdos a fin de contar con un nuevo estándar que aporte al desarrollo económico sostenible y la generación de empleo.

Asimismo, permitía expandir nuestra red de acuerdos comerciales con Australia, Nueva Zelandia, Malasia, Brunéi, Darussalam y Vietnam y se podrán mejorar ciertas disposiciones existentes en los acuerdos bilaterales con Canadá, Chile, EE.UU. de América, Japón, México y Singapur, que sean de interés de Perú.

Figura 2. Intercambio comercial del Perú con los países del TPP al cierre de 2016 - US\$ millones

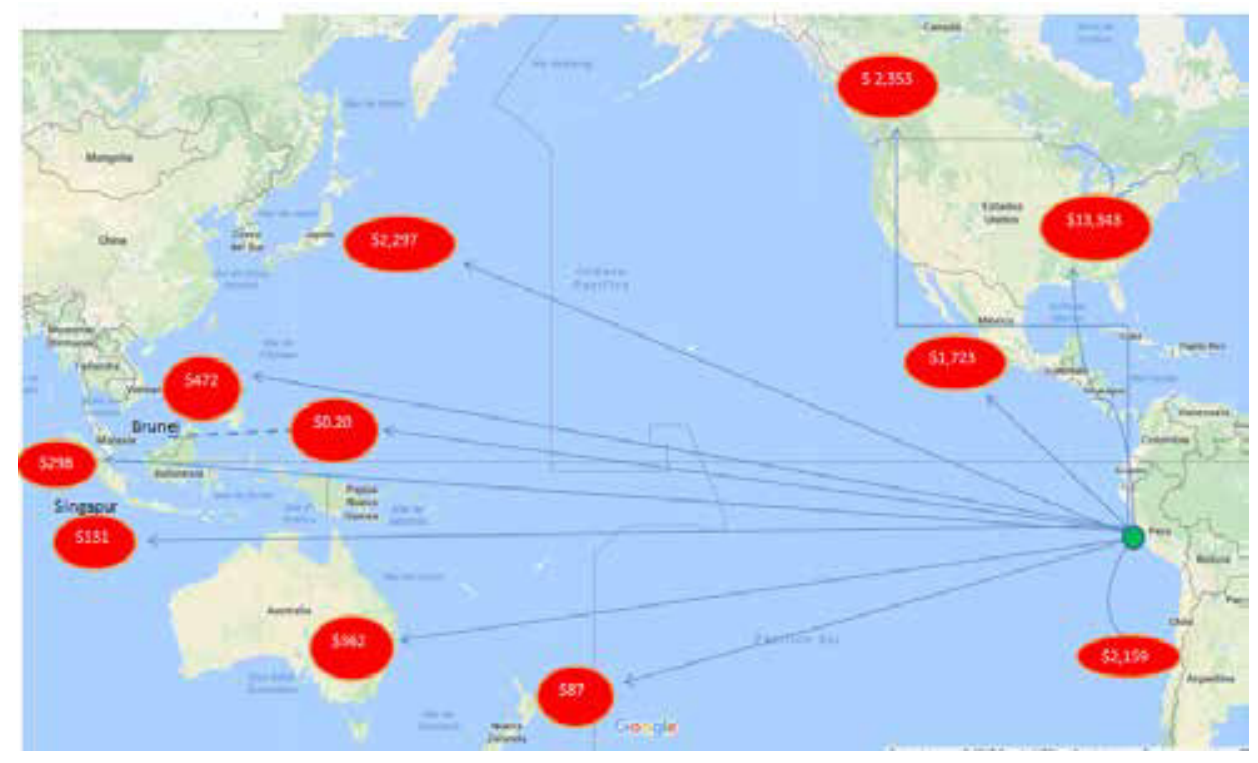

Fuente: TRADEMAP/ Imagen Google.

ElTPP permitía al Perú un relacionamiento preferencial con once importantes economías de tres continentes: América, Asia y Oceanía. Estos mercados son: Australia, Brunéi, Darussalam, Canadá, Chile, EE.UU. de América, Japón, Malasia, México, Nueva Zelandia, Singapur y Vietnam. 
Estas economías conforman un mercado potencial de casi 805 millones de habitantes, y un PBI per cápita que con excepción de Vietnam, es mayor al peruano.

En 2014, el intercambio comercial del Perú con los 11 países involucrados en la negociación representó el 36\% de las exportaciones peruanas, equivalente a 4215 mil millones de dólares. Los principales sectores exportadores fueron minería, agricultura y textil-confecciones.

\section{Características principales del acuerdo}

El gobierno de México preparó y publicó un documento que enumera las características principales del Acuerdo alcanzado (Secretaría de Economía del Gobierno de México, 2016):

- Sustancial acceso a mercados. El TPP elimina o reduce barreras arancelarias y no arancelarias de manera substancial a lo largo del espectro del comercio, incluyendo el comercio de bienes y servicios, y la inversión, de tal manera que se crean nuevas oportunidades y beneficios para nuestras empresas, trabajadores y consumidores.

- Enfoque regional sobre los compromisos. El TPP facilita el desarrollo de la producción y de las cadenas de suministro, y la fluidez del comercio incrementando la eficiencia y contribuye a nuestra meta de apoyar y crear empleos, incrementar los niveles de vida, mejorar los esfuerzos de conservación, y facilitar la integración transfronteriza, así como la apertura de los mercados nacionales.

- Afrontar los nuevos desafíos comerciales. El TPP promueve la innovación, la productividad y la competitividad al afrontar nuevos temas, incluyendo el desarrollo de la economía digital, y la función de las empresas de propiedad estatal en la economía global.

- Comercio incluyente. El TPP contiene nuevos elementos que buscan asegurar que las economías de cualquier nivel de desarrollo y empresas de cualquier tamaño puedan beneficiarse del comercio. Incluye compromisos para ayudar a las pequeñas y medianas empresas a entender el tratado, aprovechar las oportunidades que ofrece y someter a la atención de los gobiernos del TPP sus retos particulares. También contiene compromisos específicos sobre el desarrollo y la creación de capacidad comercial, para garantizar que todas las Partes sean capaces de cumplir con los compromisos establecidos en el Tratado y puedan beneficiarse al máximo.

- Plataforma para la integración regional. El TPP pretende ser una plataforma para la integración económica regional y está diseñado para que se sumen a este otras economías de la región de Asia-Pacífico. 
El acuerdo tiene un total de treinta capítulos, que comprenden el comercio y temas relacionados con él, así se desarrollaron los siguientes temas: comercio de bienes, aduanas y la facilitación comercial; medidas sanitarias y fitosanitarias; obstáculos técnicos al comercio; medidas comerciales correctivas; inversión; servicios; comercio electrónico; compras del sector público; propiedad intelectual; laboral; medio ambiente; también se incluyeron capítulos destinados a asegurar que el Acuerdo cumpla con su potencial para el desarrollo, la competitividad y la inclusión; solución de controversias; excepciones y disposiciones institucionales.

Este Acuerdo incorporó nuevos temas comerciales y transversales al comercio. Así, encontramos cuestiones relacionadas con el Internet y la economía digital, la participación de las empresas de propiedad estatal en el comercio internacional (aspecto muy común en varías economía asiáticas) y la inversión, el fomento a la mejora de la capacidad de las pequeñas empresas para aprovechar las ventajas de los tratados comerciales, entre otros temas.

A continuación se resumen los principales capítulos del acuerdo, y que fueron publicados por el Ministerio de Comercio Exterior y Turismo - MINCETUR:

\section{a) Trato nacional y acceso de mercancías al mercado}

Las partes acordaron eliminar y reducir barreras arancelarias y no arancelarias en bienes industriales, y eliminar o reducir los aranceles y otras políticas restrictivas en bienes agrícolas. El acceso preferencial que se provee a través del TPP incrementaría el comercio entre los países del TPP en este mercado de 800 millones de personas y respaldará la creación de empleo de alta calidad en las 12 Partes. La mayor parte de la eliminación arancelaria en los bienes industriales sería implementada inmediatamente, aunque, en algunos productos, los aranceles serían eliminados en periodos más amplios, tal como lo han acordado las Partes del TPP. Las reducciones arancelarias específicas acordadas por las Partes del TPP son incluidas en cronogramas que abarcan todos los bienes. Las Partes del TPP publicarían todos los aranceles y otra información relacionada al comercio de bienes para asegurar que las pequeñas y medianas empresas, así como las grandes empresas, puedan tomar ventaja del TPP.

Además, acordaron no imponer restricciones e impuestos a las exportaciones e importaciones u otras cargas que sean inconsistentes con la OMC, incluyendo a los bienes remanufacturados, los cuales promueven un reciclaje de las partes en nuevos productos.

En adición a la eliminación o reducción de aranceles, se acordó la promoción de reformas de política incluyendo la eliminación de subsidios agrícolas a la exportación, trabajar en conjunto en la OMC para desarrollar disciplinas en las empresas 
comerciales exportadoras del Estado, créditos a la exportación, y limitar los periodos de tiempo permitidos para las restricciones en exportaciones de alimentos para proveer una mayor seguridad alimentaria en la región.

\section{b) Reglas de origen y procedimientos relacionados con el origen}

Para proveer reglas de origen simples, promover cadenas de suministro regionales, y ayudar a asegurar que sean los países del TPP, en lugar de los no participantes, los principales beneficiarios del Tratado, las Partes acordaron establecer un grupo único de reglas de origen que define si un bien en particular es «originario» y, por lo tanto, elegible para recibir los beneficios arancelarios preferenciales del TPP. Las reglas de origen específicas a cada producto están adjuntas al texto del Tratado. El TPP establece la «acumulación», de manera que, en general, los insumos de una Parte del TPP son tratados de igual manera que los materiales de cualquier otra Parte del TPP, si son utilizados para producir un producto en alguna Parte del TPP.

\section{c) Textiles y prendas de vestir}

Las Partes acordaron eliminar aranceles en textiles y prendas de vestir, industrias que son importantes contribuyentes para el crecimiento económico en muchos de los mercados del TPP. La mayoría de aranceles serían eliminados inmediatamente, aunque en algunos productos sensibles serían eliminados en plazos más largos. El capítulo también incluye reglas de origen específicas que requieren el uso de hilado y tejidos de la región TPP, los cuales promoverán cadenas de abastecimiento regionales e inversión en este sector, con un mecanismo de «lista de escaso abasto» que permitirá el uso de hilado y tejidos que no estén ampliamente disponibles en la región. Además, el capítulo incluye compromisos en cooperación aduanera y fortalecimiento en la prevención de la evasión de impuestos, contrabando y fraude, así como una salvaguardia especial específica para los textiles, para responder a un daño grave o la amenaza de daño grave a la industria doméstica ante un aumento repentino de las importaciones.

\section{d) Defensa comercial}

El capítulo de Defensa Comercial promueve la transparencia y el debido proceso en los procedimientos de defensa comercial a través del reconocimiento de mejores prácticas, sin afectar los derechos y obligaciones de las Partes del TPP bajo la OMC. Establece un mecanismo de salvaguardias de transición, el cual permite a una Parte a aplicar una medida de salvaguardia de transición durante cierto periodo de tiempo si las importaciones se incrementan, como un resultado de los cortes arancelarios 
implementados bajo el TPP, causando daño grave en la industria nacional. Estas medidas podrían mantenerse por hasta dos años, con un año de extensión, pero deberán ser progresivamente liberalizadas si toman más de un año. Además, las Partes que impongan medidas de salvaguardia deberán seguir los requerimientos de notificación y de consulta. El capítulo también establece reglas que requieren que una Parte que aplique una medida de salvaguardia de transición, provea una compensación mutuamente acordada. Asimismo, las Partes no podrán imponer más de una de las salvaguardias permitidas bajo el TPP en el mismo producto al mismo tiempo.

\section{e) Inversión}

En el establecimiento de las reglas de inversión, las Partes del TPP disponen reglas que exigen políticas de inversión no discriminatorias y de protección que aseguren el Estado de derecho, mientras se proteja la capacidad de los gobiernos de las Partes para alcanzar objetivos legítimos de políticas públicas. El acuerdo provee las protecciones básicas a la inversión que se encuentran en otros acuerdos relacionados con la inversión, incluyendo el trato nacional; el trato de nación más favorecida; el «nivel mínimo de trato" para las inversiones de acuerdo con los principios del derecho internacional consuetudinario; prohibición de la expropiación que no persigue propósito público, sin un debido proceso, o sin compensación; se prohíbe los «requisitos de desempeño", tales como requisitos de contenido o tecnología local; libre transferencia de fondos relacionados con la inversión, sujeto a excepciones en el TPP para asegurar que los gobiernos retienen la flexibilidad para administrar la volatilidad de los flujos de capitales, incluyendo a través medidas de salvaguardia temporal no discriminatorias (como el control de capitales) que restringen las transferencias relacionadas a la inversión en el contexto de una crisis o amenaza de crisis en la balanza de pagos, así como ciertas otras crisis económicas; o para proteger la integridad y estabilidad del sistema financiero; y la libertad de designar altos ejecutivos de cualquier nacionalidad.

Las Partes adoptaron un enfoque de «lista negativa», lo cual significa que sus mercados están completamente abiertos a los inversionistas extranjeros, excepto donde se haya tomado una excepción (medida disconforme) en uno de los dos anexos específicos de un país: (1) las medidas vigentes en las cuales una Parte acepta la obligación de no volver sus medidas más restrictivas en el futuro, y de comprometer cualquier liberalización futura, y (2) las medidas o políticas en los cuales un país conserva plena discreción hacia el futuro.

El capítulo también establece un arbitraje internacional neutral y transparente para las controversias de inversión, con fuertes salvaguardias para evitar reclamos abusivos y frívolos; y para asegurar el derecho de los gobiernos a regular en beneficio del interés 
público, incluyendo en temas de salud, seguridad y la protección ambiental. Las garantías procedimentales incluyen: procedimientos arbitrales transparentes, comunicaciones amicus curiae, comunicaciones de Partes que no son parte de la controversia; revisión expedita de reclamos frívolos y posible compensación por los costos de los abogados; procedimiento de revisión para laudos provisionales; interpretaciones conjuntas vinculantes de las Partes del TPP; límite de tiempo para presentar un reclamo; y reglas para evitar que un demandante presente la misma demanda en un proceso paralelo.

\section{f) Comercio electrónico}

En el capítulo de Comercio Electrónico, se comprometieron a asegurar el libre flujo de la información y los datos globales que impulsan el Internet y la economía digital, sujeto a los objetivos legítimos de política pública, como la protección de la información personal. Las 12 Partes acordaron también no exigir a las compañías del TPP construir centros de datos para almacenar información como una condición para operar en un mercado del TPP y, además, que no se requiere la transferencia o el acceso al código de fuente del software. El capítulo prohíbe la imposición de derechos aduaneros a las transmisiones electrónicas, e impide que las Partes del TPP favorezcan a los productores o proveedores nacionales de dichos productos a través de medidas discriminatorias o bloqueos totales (outright blocking).

Para proteger a los consumidores, las Partes del TPP acordaron adoptar y mantener leyes de protección al consumidor, relacionadas a las actividades comerciales online cuando estas sean fraudulentas y engañosas; así como asegurar el cumplimiento de la protección de la privacidad y al consumidor en los mercados del TPP. También se exigen tener medidas para detener los mensajes electrónicos comerciales no solicitados. Para facilitar el comercio electrónico, el capítulo incluye disposiciones que incentivan a las Partes a promover un mayor comercio sin papeles entre las empresas y el gobierno, tales como el uso de formularios aduaneros electrónicos; y permitir autenticaciones y firmas electrónicas para las transacciones comerciales.

\section{g) Empresas de propiedad del Estado y monopolios designados}

Todas las Partes del TPP tienen Empresas de Propiedad Estatal (EPE), que a menudo desempeñan un papel en la prestación de servicios públicos y otras actividades; sin embargo, las Partes reconocieron el beneficio de acordar un marco de normas sobre las EPE. El capítulo sobre empresas de propiedad del Estado cubre grandes empresas estatales que se dedican principalmente a actividades comerciales. En tal sentido acordaron asegurar de que sus empresas estatales realicen compras y ventas comerciales sobre la base de consideraciones comerciales, excepto cuando hacerlo sería 
inconsistente con cualquier mandato bajo el cual una empresa estatal esté operando y que sea requerido para prestar servicios públicos. También acordaron garantizar que sus empresas estatales o monopolios designados no discriminen contra empresas, bienes y servicios de otras Partes. Las Partes acuerdan proporcionar a sus tribunales jurisdicción sobre las actividades comerciales de las empresas estatales extranjeras en su territorio, y asegurar que los órganos administrativos que regulan tanto a las empresas públicas como a las empresas privadas lo hagan de manera imparcial. Las Partes del TPP se comprometen a no generar efectos adversos a los intereses de otras Partes del TPP cuando otorguen asistencia no comercial a empresas estatales, o daño a la industria local de otra Parte cuando otorguen asistencia no comercial a una empresa estatal que produce y vende mercancías en territorio de esa otra Parte.

\section{h) Propiedad intelectual}

Este es uno de los capítulos que mayor relevancia. El capítulo de Propiedad Intelectual (PI) del TPP cubre patentes, marcas, derecho de autor, diseños industriales, indicaciones geográficas, secretos comerciales, otras formas de Propiedad Intelectual, la observancia de los derechos de Propiedad Intelectual, así como otras áreas en las que las Partes acuerden cooperar. El capítulo de PI facilitaría a las empresas la búsqueda, el registro y la protección de los derechos de Propiedad Intelectual en nuevos mercados, lo cual es muy importante, en particular para las pequeńas empresas. De igual manera, este capítulo establecía un precedente importante debido a que contiene disposiciones relativas al reconocimiento y protección de los recursos genéticos y los conocimientos tradicionales asociados. En efecto, se reconocía el vínculo existente entre los conocimientos tradicionales y los recursos genéticos y la propiedad intelectual, materias que de manera conjuntan aportan a su protección y aprovechamiento adecuado por la sociedad. A efectos de combatir la biopiratería se incluyeron disposiciones sobre cooperación e intercambio de información en los exámenes de patentes de las oficinas competentes en dichas materias de las partes.

El capítulo establecía estándares para las patentes, sobre la base de lo establecido en el Acuerdo sobre los ADPIC de la OMC y de las mejores prácticas internacionales. En el caso de las marcas, se otorgaba protección a las mismas y a cualquier otro signo distintivo que las empresas o las personas utilicen para identificar sus productos en el mercado. El capítulo también incluía medidas de transparencia y debido proceso para la protección de nuevas indicaciones geográficas, incluidas las indicaciones geográficas reconocidas o protegidas a través de acuerdos internacionales. Esto incluye el entendimiento entre las Partes respecto a la relación entre las marcas y las indicaciones geográficas, así como con relación a las excepciones para el uso de términos comunes. 
Adicionalmente, el capítulo contenía disposiciones referidas a productos farmacéuticos, las cuales facilitan tanto el desarrollo de la innovación en el campo de los medicamentos, así como la disponibilidad de medicamentos genéricos, sin perjuicio de los plazos que las Partes necesiten para la implementación de las referidas disposiciones. Por otro lado, en el capítulo se incluyeron disposiciones relativas a la protección de datos de prueba y otros no divulgados presentados para obtener la aprobación de comercialización de un nuevo producto farmacéutico o de un nuevo producto químico de uso agrícola. Además, se reafirmó el compromiso asumido por las Partes en la Declaración Ministerial de la OMC relativa al Acuerdo sobre los ADPIC y la Salud Pública (2001) y, en particular, que las Partes no están impedidas de adoptar medidas para proteger la salud pública, incluyendo los casos de epidemias tales como el VIH/SIDA.

En el caso del derecho de autor, el capítulo de Propiedad Intelectual establecía compromisos para proteger las obras, interpretaciones, ejecuciones y fonogramas, tales como canciones, películas, libros y software, así como también incluye disposiciones efectivas y balanceadas con relación a medidas tecnológicas de protección e información de gestión de derechos. Como complemento de lo anterior, el capítulo incluía la obligación para las Partes de buscar constantemente un equilibrio entre los diversos sistemas de derecho de autor, a través de, entre otras cosas, las excepciones y/o limitaciones para fines legítimos, incluido en el entorno digital. Por otro lado, el capítulo disponía que las Partes deben establecer o mantener un marco legal que incluya garantías para los Proveedores de Servicios de Internet (ISPs). Sin embargo, estas disposiciones no implicaban que los ISPs fuesen responsables de monitorear sus sistemas a fin de prevenir cualquier acto infractor.

Finalmente, las Partes del TPP acordaron fortalecer sus sistemas de observancia de los derechos de Propiedad Intelectual, lo que incluye, entre otros, el fortalecimiento de los procesos civiles, medidas provisionales, medidas en frontera, procedimientos penales y sanciones para la falsificación de marcas o piratería respecto del derecho de autor y derechos conexos cometidos a escala comercial. En particular, las Partes del TPP establecerían las herramientas legales adecuadas para impedir la apropiación indebida de los secretos comerciales, establecer procedimientos y sanciones penales para la usurpación de secretos comerciales, incluyendo el robo información por medios electrónicos, y para la grabación no autorizada de películas en cines.

\section{i) Pymes}

Las Partes tienen el interés común de promover la participación de las pequeñas y medianas empresas en el comercio y de garantizar que estas empresas compartan los beneficios del TPP. Complementando los compromisos de otros capítulos del Acuerdo en materia de acceso a mercados, reducción de trámites, acceso a Internet, 
facilitación de comercio, envíos expresos y otros, el capítulo de pymes incluía compromisos de cada Parte del TPP para crear páginas web amigables para usuarios de pequeñas y medianas empresas a fin de proporcionar información fácilmente accesible sobre el TPP, así como sobre maneras en las que pequeñas empresas puedan tomar ventaja del Tratado, incluyendo la descripción de las disposiciones relevantes para las pequeñas y medianas empresas; regulaciones y procedimientos relativos a los derechos de propiedad intelectual; regulaciones sobre inversión extranjera; procedimientos de registro de empresas; regulaciones de empleo; e información tributaria. Además, el capítulo establece un Comité de la Pequeña y Mediana Empresa que se reunirá periódicamente para examinar el grado en el que el TPP esté sirviendo a las empresas pequeñas y medianas, considerar medios para mejorar aún más sus beneficios, y supervisar las actividades de cooperación o de fortalecimiento de capacidades para apoyar a las pequeñas y medianas empresas a través de asesoría, asistencia y programas de capacitación en exportaciones para las pequeñas y medianas empresas; intercambio de información; el financiamiento para el comercio; y otras actividades.

\section{j) Transparencia y anticorrupción}

El capítulo busca promover el objetivo compartido por todas las Partes del TPP, de fortalecer el buen gobierno y abordar los efectos corrosivos que el soborno y la corrupción pueden tener en sus economías. Así, las Partes deben asegurar que sus leyes, reglamentos y disposiciones administrativas de aplicación general con respecto a cualquier asunto comprendido en el TPP estén disponibles al público y que, en la medida de lo posible, las regulaciones que puedan afectar al comercio o la inversión entre las Partes están sujetos a avisos y comentarios. Se comprometen a garantizar ciertos derechos al debido proceso de las personas interesadas en relación con procedimientos administrativos, incluyendo su pronta revisión mediante tribunales o procedimientos judiciales o administrativos imparciales. También se comprometen a adoptar o mantener leyes que penalizan el ofrecimiento o solicitud de ventajas indebidas por un funcionario público, así como otros actos de corrupción que afecten al comercio o inversión internacionales. Las Partes también se comprometen a la aplicación efectiva de sus leyes y reglamentos anticorrupción. Además, se comprometen a esforzarse por adoptar o mantener códigos o normas de conducta para sus funcionarios públicos, así como medidas para identificar y gestionar los conflictos de intereses, para aumentar la capacitación de los funcionarios públicos, a tomar medidas para desalentar los obsequios, facilitar el reporte de actos de corrupción, y establecer medidas disciplinarias o de otro tipo para los funcionarios públicos que participan en actos de corrupción.

De otro lado, este capítulo cuenta con un anexo sobre transparencia e imparcialidad para productos farmacéuticos y dispositivos médicos mediante el cual las Partes 
reconocen los principios orientados a facilitar la asistencia médica de alta calidad y mejorar la salud pública y se obligan a promover la transparencia e imparcialidad de los procedimientos de reembolso de productos farmacéuticos o dispositivos médicos.

\section{k) Nueva posición de EE.UU. Retiro del TPP}

Con fecha 23 de febrero de 2017, el presidente Donald Trump, remitió un memorándum al representante comercial de EE.UU., instruyéndolo para que retire al país de los países signatarios del TPP, retirarse permanentemente de todas las negociaciones del mismo e iniciar en la medida de lo posible negociaciones bilaterales para promover la industria estadounidense, proteger a sus trabajadores y aumentar los salarios para los estadounidenses.

Algunos analistas en EE.UU. creen consideran que, los objetivos de carácter político hegemónico que llevó a la negociación de este Acuerdo (el fortalecimiento de su liderazgo en la región del Asia Pacífico, cimentar sus alianzas y revitalizar el orden mundial) han salido volando sin esperanzas. Así, algunos consideran que el retiro ha exacerbado las dudas que en la región se han formado acerca del liderazgo y el rol que juegan EE.UU. en Asia. Esto, de acuerdo a lo indicado por Timothy Heath (2017), ha llevado a que algunos países asiáticos busquen mejorar sus relaciones con China. Un ejemplo es lo mostrado por el presidente de Filipinas, Rodrigo Duterte. Vietnam ha iniciado pasos para estabilizar su relación con el gigante asiático, al mismo tiempo que busca ampliar su acceso a mercados internacionales mediante varios acuerdos comerciales bilaterales, para así reducir su dependencia de China.

Del lado de los republicanos, el TPP, a pesar de ser un acuerdo beneficioso para las grandes corporaciones, de acuerdo a lo seńalado por los liberales estadounidenses, este es un acuerdo que contenía más perjuicios que beneficios para EE.UU. Esto, debido a que los países miembros, cedían la jurisdicción comercial de sus cortes nacionales a favor de árbitros internacionales, que incluso podían fallar en contra de decisiones soberanas. Considerando los efectos causados por la puesta en vigencia del NAFTA (North America Free Trade Agreement) que vienen sufriendo los habitantes de las antiguas zonas de producción industrial estadounidense, con altas tasas de desempleo, negocios pequeños que quebraron debido a su dependencia exclusiva de las empresas manufactureras que abandonaron el país para acogerse a producir en México, el TPP podía ser considerado un clavo más en sus ataúdes.

\section{Consecuencias}

Una de las consecuencias inmediatas tras la disposición del Gobierno estadounidense de retirarse del TPP, fue el anuncio efectuado por el jefe de la diplomacia chilena, 
Heraldo Muñoz, quien señaló que el acuerdo, tal como se conocía, ya no estaba sobre la mesa. Es decir, ya no sería impulsada su aprobación en el Congreso, porque ante la falta del mayor actor involucrado, ya no tenía razón de ser.

Esto fue seguido por el anuncio del Gobierno del Japón, que consideró que el Transpacífico es un "sinsentido» sin EE.UU. "porque se desequilibra la balanza entre intereses fundamentales».

Ambos países, a través de sus representantes recordaron que una de las cláusulas para la entrada en vigencia del TPP, es que al menos fuese ratificado por los países que representaran al menos el $85 \%$ del comercio total del bloque, lo que en esencia con la salida de EE.UU. es imposible de alcanzar.

En el caso del Perú, antes del anuncio de EE.UU. y después del mismo, se escucharon varias ideas y descripciones de escenarios catastróficos y apocalípticos sobre el comercio exterior en la era Trump, señalando que podríamos sufrir un revés en las corrientes de comercio que tenemos con el país del norte. Inclusive se propusieron alternativas que a la luz de lo que son los procesos de negociación son inviables, como por ejemplo: sustituir a EE.UU. por China, como por arte de magia.

Pero, ¿qué efectos genera para el comercio exterior peruano? La respuesta es: No tiene efecto alguno sobre el comercio peruano; nada ha cambiado.

Recordemos que nuestro comercio bilateral se encuentra enmarcado en el TLC que ambos países suscribimos en el año 2006 y pusimos en vigencia en 2009. Este TLC ha generado un gran beneficio para ambas partes, donde el comercio bilateral creció de alrededor de 8 mil millones en el año 2006 a casi 17 mil millones en el año 2013. En dicho tratado están los balances que ambos países encontramos en función a nuestros intereses y necesidades, el cual está funcionando bastante bien ya por más de siete años. Por el contrario, el TPP fue una negociación que el Perú decidió adelantar con la finalidad de ganar algunos mercados adicionales como Australia, Nueva Zelandia, Malasia, entre otros; pero nunca fue prioridad dentro del TPP, buscar una modificación de las relaciones bilaterales Perú - EE.UU. Solo queríamos mostrar una vez más que podíamos estar en un club de grandes. ¿Entonces por qué tanto miedo a la salida de EE.UU. de un proceso que ya se perfilaba trunco años atrás?

La respuesta viene del lado de los otros miembros del TPP, que definitivamente han visto mermados sus intereses de lograr un acuerdo comercial con EE.UU., en el marco de una negociación «plurilateral». Ese es el caso de Australia, Nueva Zelandia y Malasia, que han visto sus esfuerzos esfumarse en forma inmediata. Otros países como México, Canadá y Vietnam, buscaban con este TPP, mejorar los alcances y regulaciones de los tratados que ya tenían con EE.UU., de manera tal que pudieran ganar mayor competitividad en el mercado a donde todos los países queremos llegar. 
Lo cierto es que para el Perú, la salida de EE.UU. podría convertirse más que en un problema, en una gran oportunidad comercial. Solo como ejemplo, en el sector textilconfecciones, el Perú continuará con el acceso libre al mercado estadounidense sin tener una competencia agresiva por parte de países como Vietnam y Malasia, que buscaban tener el mismo acceso que nuestro país, lo cual hubiera eliminado de plano cualquier ventaja que ya teníamos ganada por la ardua negociación de 2006. Pero también se abren grandes posibilidades de aumentar nuestras exportaciones a EE.UU. considerando que la era Trump pretende renegociar y poner algunos aranceles a producciones provenientes de los otros miembros NAFTA (México y Canadá), así como a China.

Estas restricciones podrían generar indirectamente una mayor competitividad en las exportaciones peruanas, las cuales no solo tendrán mayores oportunidades para los productos terminados o finales, sino también para aquellos productos intermedios e insumos que serán necesarios para la industria de EE.UU. que Trump ha prometido reflotar. Por ello, dejemos de lado el miedo sobre una situación inexistente y capitalicemos una oportunidad más que se nos presenta en el camino. Puede ser que el Make America Great Again sea un excelente escenario para fortalecer los lazos estratégicos entre Perú y EE.UU.

\section{Referencias}

Biblioteca del Congreso Nacional de Chile (2006). Historia de la Ley Decreto Supremo $N^{\circ} 354$ Recuperado de http://www.leychile.cl/Navegar/scripts/obtienearchivo?id=recursosleg ales/10221.3/43467/2/HLDto354.pdf

Heath, T. (2017). Rand Corporation. Recuperado de https://www.rand.org/blog/2017/03/ strategic-consequences-of-us-withdrawal-from-tpp.html

Ministerio de Comercio y Asuntos Exteriores de Nueva Zelandia (2005). Trans-pacific strategic economic partnership agreement. Recuperado de https://www.mfat.govt.nz/ assets/_securedfiles/FTAs-agreements-in-force/P4/transpacific-sepa-nia.pdf

Secretaría de Economía del Gobierno de México (2016). Resumen Ejecutivo Tratado de Asociación Transpacífico. Recuperado de http://www.gob.mx/cms/uploads/ attachment/file/35623/TPP_resumen_ejecutivo_es.pdf

SICE-Sistema de Información sobre Comercio Exterior (2017). Acuerdo Estratégico Transpacifico de Asociación Económico. Recuperado ede http://www.sice.oas.org/ Trade/CHL_Asia_s/TransPacific_ind_s.asp

Stratford Worldview (2008). United States: Committed To Joining Trans-Pacific Trade Group008). Recuperado de https://www.stratfor.com/analysis/united-states-committed-joiningtrans-pacific-trade-group

Fecha de recepción: 11 de mayo de 2017

Fecha de aprobación: 29 de mayo de 2017 